\title{
METROPOLIZAÇÃO E MOBILIDADES TURÍSTICAS EM/ENTRE SÃO PAULO E BAIXADA SANTISTA EM TEMPOS DE PANDEMIA
}

\author{
METROPLIZATION AND TOURISM MOBILITIES IN/BETWEEN SÃO PAULO AND BAIXADA SANTISTA IN PANDEMIC \\ TIMES
}

\author{
METROPOLIZACIÓN Y MOVILIDADES TURÍSTICAS EN/ENTRE SÀO PAULO Y BAIXADA SANTISTA EN TIEMPOS DE \\ PANDEMIA
}

\section{RESUMO}

Este artigo é assentado no reconhecimento de que há uma imbricada relação entre urbanização, metropolização e turismo o que, por conseguinte, orienta a análise acerca dos desdobramentos da pandemia da COVID-19 sobre o turismo de São Paulo e da Baixada Santista. Mais que simplesmente refletir sobre os quantitativos envolvidos, busca-se qualificar o debate para além de uma suposta relação de causa e efeito, considerando a complexidade subjacente ao tema e aos estudos de caso. Assumindo que a realidade urbana entre São Paulo e Baixada Santista tem muitos paralelos no Brasil e no mundo, este estudo contribui para a interpretação do fenômeno do turismo em dinâmicas metropolitanas complexas. O desenvolvimento de certas práticas sob a égide de um "turismo de pandemia" indica uma acomodação na narrativa e nas dinâmicas do turismo atualmente, a despeito da gravidade e das incertezas sobre os desdobramentos da pandemia.

Palavras-chave: urbanização, metropolização, mobilidades, turismo, COVID-19.

\section{ABSTRACT}

This article is based on the recognition that there is an imbricated relationship between urbanization, metropolization and tourism, which, therefore, guides the analysis about the consequences of the pandemic of COVID-19 on the tourism of São Paulo and Baixada Santista. More than simply reflecting on the amounts involved, it seeks to qualify the debate beyond a supposed cause and effect relationship, considering the complexity underlying the theme and the case studies. Assuming that the urban context between São Paulo and Baixada Santista has many parallels in Brazil and in the world, this study contributes to the understanding of the phenomenon of tourism in complex metropolitan dynamics. The development of certain practices under the umbrella of "pandemic tourism" indicates an accommodation in the narrative and dynamics of tourism today, despite the seriousness and uncertainties about the consequences of the pandemic.

Keywords: urbanization, metropolization, mobilities, tourism, COVID-19.

\section{RESUMEN}

Este artículo parte del reconocimiento de que existe una relación imbricada entre urbanización, metropolización y turismo, que, por tanto, orienta el análisis sobre las consecuencias de la pandemia de COVID-19 sobre el turismo en São Paulo y Baixada Santista. Más que simplemente reflexionar sobre los montos involucrados, busca calificar el debate más allá de una supuesta relación de causa y efecto, considerando la complejidad que subyace en el tema y los casos de estudio. Asumiendo que la realidad urbana entre São Paulo y Baixada Santista tiene muchos paralelos en Brasil y en el mundo, este estudio contribuye a la interpretación del fenómeno del turismo en dinámicas metropolitanas complejas. El desarrollo de ciertas prácticas bajo el paraguas del "turismo pandémico" indica un acomodo en la narrativa y dinámica del turismo actual, a pesar de la gravedad e incertidumbre sobre las consecuencias de la pandemia.

Palabras-clave: urbanización, metropolización, movilidades, turismo, COVID-19.

\author{
Thiago Allis ${ }^{a}$ \\ Rita de Cássia Ariza da Cruz a \\ Daniel Barreti ${ }^{\text {a }}$ \\ Isabella Maria Beil ${ }^{a}$ \\ ${ }^{a}$ Universidade de São Paulo (USP), São \\ Paulo, SP, Brasil
}

DOI: $10.12957 /$ geouerj.2021.61342

Correpondência: thiagoallis@usp.br

Recebido em: 11 mar. 2021 Aceito em: 22 jun. 2021 


\section{INTRODUÇÃO}

A atividade turística, por essência, se constitui de fluxos de viajantes motivados pelas mais variadas demandas, desejos e necessidades. Exceção a certos tipos de deslocamento (por exemplo, migrações e refúgio), as mobilidades turísticas expandem-se de forma sustentada, há várias décadas, na esteira de transformações socioeconômicas e também tecnológicas. Com a generalização global de processos econômicos e sociais, práticas turísticas chegam a cifras bilionárias, atingindo mais de 1,4 bilhão de chegadas internacionais em $2019^{1}$ - sem considerar os importantes fluxos domésticos, que se avolumam cada vez mais com as transformações econômicas e sociais em nações populosas, como China, Índia, Brasil, México, Indonésia, etc.

Neste contexto, a crise sanitária trazida pela SARS-CoV-2 impactou o turismo de forma avassaladora, refreando fluxos, fechando estabelecimentos comerciais - temporária ou definitivamente, e trazendo prejuízos não apenas econômicos, mas também sociais e emocionais. Localidades economicamente mais dependentes da atividade (sobretudo as receptoras de turistas, mas não apenas) tenderam a ressentir-se mais drasticamente com os efeitos da crise, mas isso derivou e deriva de um complexo feixe de fatores profundamente imbricados de formas não exatamente explícitas, nem sempre expressos pelas estatísticas.

Sobretudo em países pobres e em desenvolvimento, a metropolização, um dos importantes desdobramentos das transformações em curso no século XX, relaciona-se, diretamente, com os efeitos da pandemia no turismo. No caso brasileiro, dá-se, em um primeiro momento, a formação de regiões metropolitanas intimamente relacionadas à concentração espacial da atividade industrial em fragmentos do território nacional, com destaque para as cidades de São Paulo e Rio de Janeiro e seus entornos imediatos. Como alerta Souza (2004, p. 57), todavia, a complexa urbanização brasileira existe em uma "estreita associação com a complexidade de nossa economia [...] e refletindo os padrões cambiantes de concentração e desconcentração industrial". As Regiões Metropolitanas de São Paulo e da Baixada Santista são, do ponto de vista normativo, as mais antigas do estado. A RMSP, criada por lei federal em 1973 e a RMBS, por lei estadual (conforme prerrogativa estabelecida na CF de 1988), em 1996. Outras quatro regiões metropolitanas foram criadas pelo governo do estado já no século XXI, sendo estas a Região Metropolitana de Campinas (2000), a Região Metropolitana do Vale do Paraíba e Litoral Norte (2012), a Região Metropolitana de Sorocaba (2014) e a Região Metropolitana de Ribeirão Preto (2016) e outra encontra-se em fase de criação, a Região Metropolitana de Piracicaba.

Dados demográficos e de produção de riqueza atestam a importância econômica das regiões metropolitanas de São Paulo e da Baixada Santista. De acordo com a Fundação SEADE (2020), a estimativa da

\footnotetext{
${ }^{1}$ Conforme dados da UNWTO (2020), disponíveis em https://www.unwto.org/global-and-regional-tourism-performance. Acesso em 7 de março de 2021.
} 
população da RMSP (com seus 39 municípios) para o ano de 2020 é de 21.138.247 habitantes (cerca de 12 milhões habitantes somente na capital) e para a RMBS (9 municípios) é de 1.831.884. Juntas, essas regiões abrigam, portanto, quase $11 \%$ da população brasileira. Por outro lado, a RMSP respondeu sozinha por cerca de $17,3 \%$ do PIB nacional ${ }^{2}$ segundo dados de 2019, expressando a gigantesca concentração de riqueza em apenas $0,7 \%$ dos 5570 municípios brasileiros. Os territórios que formam essas regiões dizem respeito a áreas que remontam ao início da ocupação europeia (século XVI), e que passaram por transformações profundas, especialmente nos últimos cerca de 200 anos, com a cultura cafeeira e com o processo de industrialização. Desde esse passado longínquo, as relações entre os núcleos urbanos de São Paulo e Santos, por exemplo, são estreitas, envolvendo a circulação de mercadorias e de pessoas por meio de estradas e ferrovias (como a Estrada de Ferro Santos-Jundiaí, inaugurada em 1867), que desde aquele tempo já ligavam a capital ao porto de Santos, hoje considerado o maior complexo portuário da América Latina ${ }^{3}$.

Diferentemente, entretanto, do que se passara no século XIX e início do XX, em que a economia nacional e regional estava fundamentada basicamente no comércio de commodities agrícolas e minerais e na atividade industrial nascente, essas regiões, tal como ocorrido em muitos lugares pelo mundo, viram, no último quartel do século XX, o setor de serviços assumir papel importante na organização de sua atividade econômica. E é nesse contexto histórico que também o turismo, que amalgama múltiplos serviços (como transporte, hospedagem e alimentação, por exemplo), emergiu com grande potência - apesar das precoces manifestações de atividade balnear em Santos e Guarujá, ainda no final do século XIX.

Assim, em um contexto de relações espaciais complexas, essas regiões apresentam diferentes formas e graus de relação com o turismo, particularmente no que se refere a serem núcleos receptores e emissores para diferentes públicos. Por isso mesmo, com a pandemia da COVID-19, sofreram e responderam de maneiras distintas aos seus impactos, dada principalmente a natureza do turismo que se processa no interior e entre as áreas metropolitanas.

Diante deste quadro, perguntamo-nos sobre como essa dimensão urbana integrada, definida por dinâmicas territoriais de regiões metropolitanas específicas, modula o fenômeno turístico e, ainda mais especificamente, como os desdobramentos da pandemia se manifestam no bojo de processos espaciais constituídos historicamente. Neste artigo, propomos uma abordagem crítica desses processos a partir de um

\footnotetext{
2 Fonte: Fundação SEADE, 2020. Disponível em https://www.seade.gov.br/pib-do-estado-de-sao-paulo-cresceu-25-em-2019/. Acesso em 24 de fevereiro de 2021.

${ }^{3}$ Segundo a Autoridade Portuária de Santos. Disponível em http://www.portodesantos.com.br/conheca-o-porto/o-porto-de-santos/. Acesso em 3 de fevereiro de 2021.
} 
estudo de caso sobre as imbricações turísticas entre a maior metrópole do Brasil e a Região Metropolitana da Baixada Santista ${ }^{4}$.

\section{Aportes metodológicos}

Apesar de a análise recair sobre duas regiões metropolitanas, será priorizada a cidade de São Paulo, como representação mais contundente da dinâmica turística de sua Região Metropolitana. Já no que se refere à RMBS, buscou-se levantar e parear dados de todos os municípios constitutivos, com exceção de Cubatão, dada a baixa expressividade do turismo em seu território.

A pesquisa se baseia na coleta e tratamento de dados ao longo de 2020 e até fevereiro de 2021, essencialmente em fontes secundárias (relatórios e informações oficiais). De maneira complementar, buscaram-se informações mais contextuais em veículos da imprensa digital (periódicos, portais e sites de notícia). Iniciamos este artigo com algumas reflexões sobre a relação entre urbanização, metropolização e turismo, ressaltando alguns aspectos históricos que unem a cidade de São Paulo à Baixada Santista como manifestação complexa das mobilidades turísticas contemporâneas. A partir daí, traçamos uma breve caracterização do turismo nesses lugares no momento pré-pandemia para, na sequência, apresentarmos dados que expressam o impacto da crise sanitária no turismo tanto em São Paulo como na Baixada, buscando, em seguida, identificar fases desse processo. Por fim, analisamos as medidas e os indicativos de retomadas das atividades do setor, considerando os conflitos envolvidos.

\section{Urbanização, metropolização e turismo: a megarregião Rio de Janeiro-São Paulo}

Para além de demarcações institucionalizadas (RMSP e RMBS, no caso em tela), é necessário reconhecer que a dinâmica das regiões metropolitanas extrapola escalas administrativas, articulando-se, pois, em função da natureza do fenômeno que se observa, a despeito das dimensões físicas.

Para se compreender a "produção do espaço metropolitano" e os processos de metropolização, é indispensável uma "análise multiescalar", que, por sua vez, "transcende o espaço metropolitano em si" (MORAES, 2006, p. 25-26). De fato:

[...] é cada vez mais evidente que a escala é um problema não apenas dimensional, mas também, e profundamente, fenomenal. (...). Na realidade, o que é visível no fenômeno e o que possibilita sua mensuração, análise e explicação depende da escala de observação (CASTRO, 2002, p. 130-131, grifo nosso).

\footnotetext{
${ }^{4}$ A Região Metropolitana da Baixada Santista (RMBS), criada por pela Lei Complementar 815, de 1996, compõe-se dos municípios de Bertioga, Guarujá, Cubatão, Santos, São Vicente, Praia Grande, Itanhaém, Mongaguá e Peruíbe. Disponível em: www.agem.sp.gov.br. Acesso em: 17 de março de 2021.
} 
Nesta seara, o conceito de região ampara o debate, na medida em que remete a uma porção de território que tem "uma unidade interna, uma coesão" e que essa unidade e integração "não é definida pela continuidade de elementos espaciais, nem pela homogeneidade de fenômenos, mas pela integração que apresentam" (LENCIONI, 2015, p. 10). Os elementos constitutivos dessa integração, esclarece Lencioni (2015, p. 74) , são "os fluxos, os movimentos, as ligações (linkages) entre as partes, bem como as complementariedades entre partes e funções, que se dão pela mediação de diversas dinâmicas e processos que se desenvolvem no interior da região". De partida, portanto, o sentido metropolitano aqui não pode ser confundido com a "região metropolitana relacionada ao processo de industrialização e urbanização que caracterizaram boa parte do século XX" (ibid).

Por outro lado, a região não é uma entidade ensimesmada. Pelo contrário, em um mundo regido por fluxos de toda natureza, as regiões são também produto e produtoras de relações extravertidas, nacionais e internacionais. No que se refere às suas dinâmicas internas, a "cidade-região" se constitui por uma metropolização que "corresponde a um momento mais avançado do processo de urbanização" (LENCIONI, 2006, p. 72). E a autora segue perguntando: “Qual o limite, qual o tamanho da cidade-região? O limite territorial dessa região é fluido e difícil de delimitar, já que essa se constitui, por excelência, num espaço de fluxos pela presença de inúmeras redes interconectadas" (ibid, p. 73).

Esses questionamentos amoldam-se claramente ao caso de São Paulo, cidade mundial e núcleo metropolitano com a economia mais pujante do país, e Santos, com sua destacada função portuária. Para além de suas funções particulares, essas aglomerações articulam-se de distintas formas, sendo que as funções turísticas e assemelhadas têm um papel altamente relevante há mais de 100 anos - em que pese a constante facilitação de conectividades (caminhos terrestres, ferrovias, autoestradas), transformações de hábitos (a descoberta e a valorização da praia como espaço de lazer) e expansão de demandas e ofertas pari passu com a crescente imbricação das dinâmicas econômicas, sociais, espaciais deste imenso aglomerado urbano, ainda que descontínuo.

Ao analisar o alcance e a participação de fluxos internacionais na produção da metrópole de São Paulo, Arroyo discute a "espessura" de uma região metropolitana, cujo tempo "vai se transmitindo seletivamente a todo o território" (2004, p. 101). Aproveitando-nos desta análise, poderíamos relembrar que essa propagação de influências - de dentro para fora e também ao contrário - alcança escalas mais próximas, incluindo, como no caso em tela, as interfaces com territórios próximos. Como argumentaremos adiante, a pandemia impôs um conjunto de situações que fazem a espessura da metrópole paulistana variar em função de atividades típicas (ou nem tanto) de turismo - especialmente em direção às áreas lindeiras aos seus limites, como a Baixada Santista; o Circuito das Águas, nas imediações de Campinas; os eixos Nordeste sobre a Rodovia Fernão Dias) e Oeste (ao longo das Vias Castello Branco e Raposo Tavares), para citar alguns. 
É sob essa perspectiva que compreendemos o turismo em São Paulo e na Baixada Santista, ou seja, como expressão concreta da inserção desses lugares na economia nacional e mundial, mas também como resultante de ligações e complementariedades internas a esse fragmento da megarregião Rio de Janeiro-São Paulo (Figura 1). Esta seria "a urbanização regional de maior expressão no Brasil e no hemisfério sul", a qual se caracteriza por "intensa integração produtiva, forte integração com a economia global e grande densidade de movimentos pendulares", conforme aponta Lencioni, 2015, p. 10-11).

Figura 1. Megarregião Rio de Janeiro-São Paulo. Fonte: Lencioni (2015, p. 13)

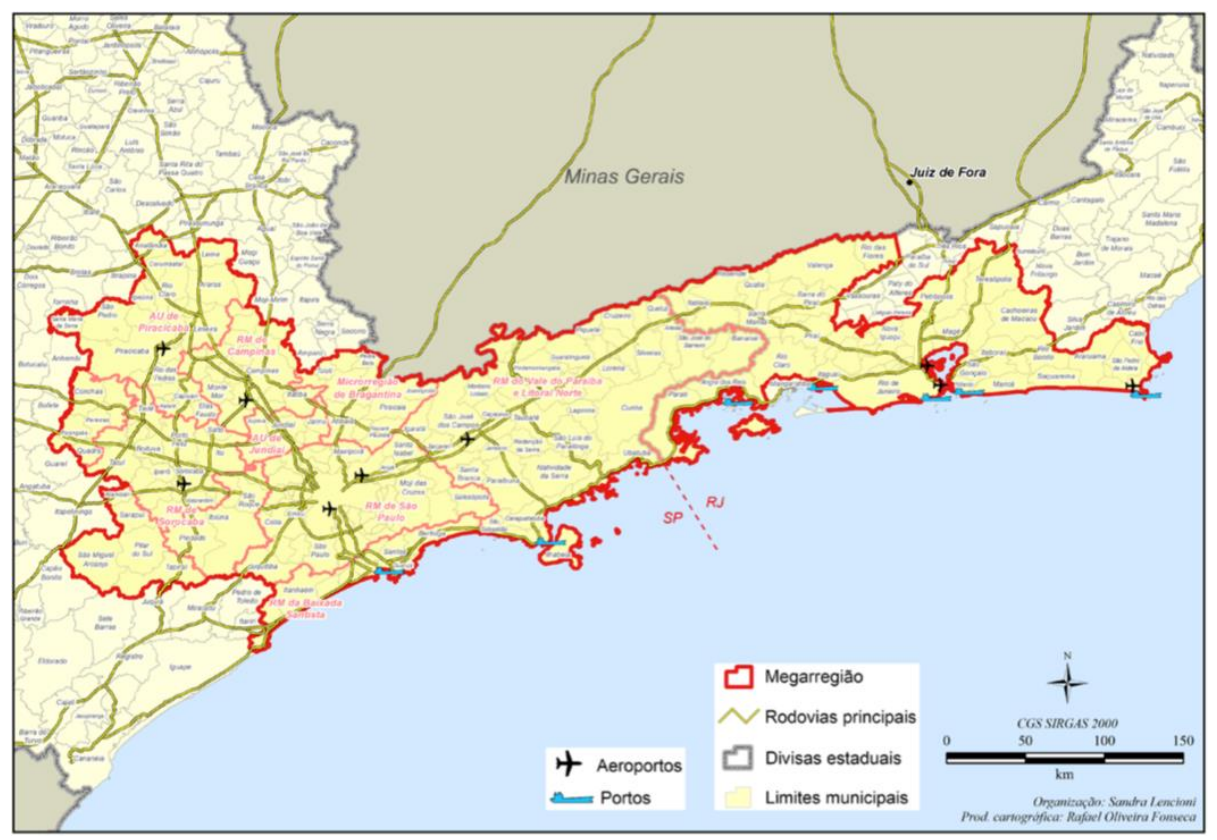

Reconhecendo, portanto, a "dispersão urbana" ${ }^{5}$ como tônica do processo de metropolização, somos instados a re-discutir a noção de origem e destino, tão central para a compreensão do turismo nas suas dimensões espacial e territorial (ALLIS, 2014). Em um "mundo-cidade" (AUGÉ, 2010) ou "urbanização planetária", incorporam-se processos dialéticos de "concentração" e "extensão" (BRENNER, 2013, p. 102), em que pesem formas, processos e funções superpostos de maneiras não-lineares ou homogêneas. Assim, o basilar contraste entre o familiar (casa) e o desconhecido (destinação turística) se dilui quando miramos para as mobilidades de caráter turístico que se processam neste composto urbano estendido - seja a pequenas distâncias, como é o caso da megarregião Rio de Janeiro-São Paulo, seja nos deslocamentos entre os grandes e longos eixos de fluxos globais. De fato, algumas práticas de turismo e lazer durante a pandemia da COVID-

\footnotetext{
5 “A dispersão urbana tende a ocorrer nas áreas correspondentes às aglomerações metropolitanas e semimetropolitanas e ao redor dos núcleos isolados de maior porte. Nesse sentido, é um processo de dispersão periférica. Mas é também parte de um outro, igualmente importante, o da concentração urbana em escala microrregional. Ela se dá nas áreas em que ocorrem as mudanças nas formas de produção, mas principalmente nas formas de consumo, com a adoção de modos de vida metropolitanos. Nessas áreas, as inovações nos setores de transportes e comunicações permitem a descentralização das unidades industriais, de comércio e de serviços, além da de áreas residenciais" (REIS, 2015, p. 94, grifo nosso).
} 
19 reacenderam debates sobre a ideia de "turismo de proximidade" ou "staycation", considerando a relativização das condicionantes espaço-temporais. Viu-se emergir, com alguma recorrência na imprensa, o estímulo à "experiência de ser turista na própria cidade" (MOLINA, 2020, on line) ou a busca por "viagens mais curtas, quase sempre no esquema bate-volta, procura por lugares abertos, restaurantes arejados e proximidade com a natureza" (AMENDOLA, 2020, on line), expondo novas e contingentes dinâmicas turísticas no espaço da metrópole e seus arredores.

Por mais que a mobilidade, como categoria de análise específica, não seja explorada a fundo neste trabalho, destacamos alguns aspectos que dilatam as noções sobre seu significado. O chamado "paradigma das novas mobilidades" ou "giro das mobilidades" (SHELLER, 2017; CRESSWELL, 2006; SHELLER, URRY, 2006; URRY, 2000) não representa um campo de estudo restrito aos deslocamentos físicos entre pontos do território (através do transporte de corpos), tampouco a ideia de fluxo contínuo, sob o mantra da globalização, de uma sociedade em rede. Urge, então, reconhecer fricções e diferentes atributos que moldam a propensão dos indivíduos à mobilidade - que Kaufmann et al. (2015) chamam de "motilidade" -, no marco da qual se inclui o turismo. Com efeito, as disputas e assimetrias no acesso a certos espaços de turismo da megarregião Rio de Janeiro-São Paulo durante a pandemia expõem diferentes capacidades dos indivíduos moverem-se - ou seja, distintos graus de motilidade (CARNEIRO, ALLIS, 2021).

Com ênfase no fenômeno do turismo, assumida e necessariamente multiescalar, seguem-se análises sobre como este se constitui na interface entre duas grandes áreas urbanas paulistas e, ademais, como a pandemia impõe novas dinâmicas à organização da atividade, particularmente no tocante aos rebatimentos espaciais. Observaremos especialmente como as (i)mobilidades se processam no interior e entre as duas regiões metropolitanas, a partir de situações presentes e possíveis desdobramentos no futuro próximo.

Linkages históricos entre São Paulo e Baixada Santista: turismo e complementariedades regionais

Nos primórdios do século XX, o poeta Vicente de Carvalho, então habitante de São Paulo, construiu o que seria a primeira casa de veraneio do atual município de Bertioga cujo terreno fora adquirido por ele em 1917 (SABINO, 2007). Naquele tempo, Bertioga era um bairro de Santos e somente décadas mais tarde, em 1991, se emanciparia. São Paulo, por sua vez, vivia um boom de crescimento demográfico provocado, de um lado, pela pujança econômica possibilitada pela cultura do café e, por outro, pelo desenvolvimento da primeira 
fase de sua industrialização, fatores que, conjugados, resultaram em um crescimento de praticamente $100 \%$ de sua população em um lapso de 20 anos entre $1900^{6}$ (240 mil habitantes) e $1920^{7}$ (579 mil habitantes).

A função balneária de Bertioga somente se desenvolveria mais tarde com melhorias nas condições de acesso a suas praias; uma delas promovida pelo empresário José Ermírio de Moraes que, por conta de interesses próprios, construiu uma ligação entre Guarujá e Bertioga, ainda na década de 1940. Mas um impacto importante sobre toda a Baixada Santista foi a inauguração da Via Anchieta (SP 150), em 1947, especialmente no que concerne ao desenvolvimento de um turismo litorâneo de massa, no bojo do desenvolvimento das forças produtivas no estado de São Paulo, entre as quais as infraestruturas de circulação.

Embora a melhor e mais segura acessibilidade rodoviária tenha impulsionado o turismo de massa de habitantes da cidade de São Paulo e arredores em direção às praias da Baixada, esse movimento é anterior, como descrito por Odette Seabra (1979) em "A muralha que cerca o mar", pois desde os primeiros anos do século XX, famílias da aristocracia cafeeira paulista adquiriram terreno à beira mar em Santos para instalar suas chácaras de veraneio. Além disso, a Estrada de Ferro Santos-Jundiaí (originária na The San Paulo Railway Co.) possibilitou o acesso ao mar também para a classe trabalhadora, habitante do "planalto" que, nas primeiras décadas do século passado começou a "descer" para o litoral durante finais de semana, feriados e férias numa demonstração de que a invenção da praia no imaginário ocidental (CORBIN, 1988), que diz respeito a um processo amplo de valorização dos ambientes praianos por práticas de lazer da sociedade moderna, também chegava por aqui.

Assim, ao longo do século XX, enquanto a cidade de São Paulo cresce demográfica e economicamente de forma vertiginosa, ela se torna, também um polo emissor de turistas não apenas para o litoral, mas construindo laços com municípios costeiros mais próximos à capital com uma importante influência, até os dias atuais, na produção dos espaços urbanos dessas localidades, tal como expresso pelo fenômeno das residências secundárias e pelo desenvolvimento do setor de serviços de hospedagem, alimentação e lazer nesses lugares. Paralelamente, São Paulo, que se encontra entre as maiores cidades do mundo em termos populacionais, torna-se também um polo de atração de turistas de diferentes lugares do globo e de todas as regiões do Brasil.

Turismo em São Paulo e Baixada Santista: uma perspectiva contemporânea e pandêmica

\footnotetext{
${ }^{6}$ BRASIL. Synopse do Recenseamento 1900. Disponível em https://biblioteca.ibge.gov.br/visualizacao/livros/liv25474.pdf. Acesso em 24 de fevereiro de 2021.

${ }^{7}$ BRASIL. Recenseamento de 1920. Disponível em https://biblioteca.ibge.gov.br/visualizacao/livros/liv6478.pdf. Acesso em 24 de fevereiro de 2021.
} 
A concentração populacional e de riqueza na RMSP, e mais especificamente na capital paulista, é geradora da maior demanda solvável do país. Em outras palavras, a cidade de São Paulo concentra a maior parcela da população com tempo e dinheiro disponíveis para o lazer. Tal fato explica, em parte, a demanda turística da Baixada Santista e de sua relação com a metrópole de São Paulo, pois esta demanda também é fruto de uma necessidade socialmente construída e peculiar dos grandes centros urbanos: a fuga de um cotidiano estressante.

Portanto, é na relação com a capital paulista que se caracteriza o uso turístico contemporâneo de oito municípios que compõem a costa da Baixada Santista (Bertioga, Guarujá, Santos, São Vicente, Praia Grande, Itanhaém, Mongaguá e Peruíbe). Desde o final do século XIX, principalmente a partir da primeira metade do século XX, os municípios da Baixada Santista assumem esta função balneária em relação aos municípios que integram a RMSP, sobretudo a cidade de São Paulo.

Essa relação historicamente construída demanda que a percepção e a análise de alguns fenômenos somente possam ser efetuadas em sua complexidade quando as duas regiões são consideradas em associação. Um exemplo é a questão das segundas residências, que será tratada adiante. Por sua vez, a pandemia, como um novo fenômeno contemporâneo, incidiu com diferentes particularidades e desdobramentos seja na RMSP, seja na RMBS. Assim, os tópicos seguintes pretendem expor dados e analisar as duas regiões no que se refere a algumas especificidades, mas também ressaltar os vínculos existentes entre ambas, que se transformam e se acentuam no momento atual.

São Paulo e pandemia: (i)mobilidades turísticas entre o planalto e o mar

Logo nos primeiros meses de 2020, o Observatório de Turismo e Eventos da cidade de São Paulo apontou os severos impactos da pandemia sobre o setor turismo. O seu primeiro Boletim ${ }^{8}$ relativo a este tema, indicava por exemplo, uma queda na taxa de ocupação hoteleira comparando-se março de 2019 e de 2020, de $65,4 \%$ para $39,7 \%$. Considerando esse mesmo período, a queda no volume de passageiros nos terminais rodoviários foi de $43,4 \%$ e de $35,4 \%$ no volume de passageiros transportados nos três principais aeroportos que atendem a capital (Viracopos, Congonhas e Guarulhos).

No que concerne aos eventos de diferentes naturezas, o primeiro Boletim do Observatório do Turismo de São Paulo apontava, com base em levantamento realizado pela empresa Visite São Paulo (São Paulo Visitors

\footnotetext{
8 OBSERVATÓRIO DO TURISMO DA CIDADE DE SÃO PAULO. Impactos da pandemia de Covid-19 no turismo de São Paulo. Maio/2020. Disponível em http://www.observatoriodoturismo.com.br/pdf/01BoletimSPCovid 05mai.pdf. Acesso em 2 de março de 2021.
} 
and Convention Bureau), para o cancelamento de 114 eventos entre março e junho de 2020, para os quais havia um público estimado em 5 milhões de pessoas.

Já no seu Boletim n. 2 de $2020^{9}$, o Observatório trouxe dados ainda mais impactantes: queda de $91,4 \%$ na taxa de ocupação hoteleira comparando-se abril de 2019 e de 2020, e de 75,2\% considerando-se apenas os hostels da cidade. A movimentação nos terminais rodoviários, neste mesmo período, tivera queda de 90,4\% enquanto a movimentação de passageiros em aeroportos caíra 92,8\%. A partir daquele momento da crise até os dias atuais (março de 2021) os eventos de todo tipo foram sendo sistematicamente cancelados ou adiados, incluídos aí grandes eventos como a Parada Gay, a corrida de Fórmula 1, o Réveillon na Paulista e o Carnaval 2021 - o que para o turismo numa grande cidade como São Paulo é altamente impactante.

Além disso, o chamado turismo de negócios, um dos mais importantes segmentos da cidade de São Paulo, assistiu a substituição das viagens corporativas por reuniões remotas, on line, resultado do confinamento de trabalhadores de diferentes escalões em suas casas.

O que se passou em São Paulo desde o início da crise foi um reflexo do que, em verdade, aconteceu no mundo todo: fechamento de fronteiras, cancelamento de voos, restrições à circulação de pessoas e outras medidas sanitárias visando o combate à proliferação da doença. Assim, em um processo brusco de interrupção de mobilidades, o turismo, uma prática social e atividade econômica que implica, basicamente, no deslocamento de pessoas pelos territórios, tornou-se um dos setores mais afetados pela pandemia.

O saldo desse movimento em 2020 foi, resumidamente, uma perda de 58,7\% na ocupação dos hotéis, de $53,1 \%$ para os hostels, de $51,9 \%$ no movimento de passageiros nos terminais rodoviários e de $55 \%$ nos aeroportos que atendem a cidade (OBSERVATÓRIO DE TURISMO E EVENTOS, s/d ${ }^{10}$ ). Esses dados só não são piores porque na alta temporada de verão das viagens de turismo de 2020, abarcando os meses de janeiro e fevereiro, embora os rumores sobre a pandemia viessem se intensificando, nenhuma medida de restrição à mobilidade de pessoas havia ainda sido tomada, o que veio a ocorrer no final de março.

O outro lado dessa moeda nos faz lembrar que a cidade de São Paulo e seu entorno metropolitano seguiram sendo o principal polo emissor de turistas do país. Se, por um lado, a cidade deixou de receber milhões de visitantes, por outro, os desejos de viagem dos habitantes da metrópole tiveram de ser adiados e ressignificados em função da crise sanitária. É assim que podemos falar em uma espécie de "turismo da pandemia", espacialmente restrito, relacionado a destinos geograficamente mais próximos dos locais de

9 OBSERVATÓRIO DO TURISMO DA CIDADE DE SÃO PAULO. $2^{\circ}$ Semestre/2020. Disponível em http://www.observatoriodoturismo.com.br/pdf/BOLETIM SP COVID 19 Edição 2.pdf. Acesso em 2 de março de 2021.

${ }_{10}$ Disponível em http://www.observatoriodoturismo.com.br/pdf/CENTRAL ANO 2020.pdf. Acesso em 2 de março de 2021. 
residência de turistas e é aqui que encontramos o "fio de Ariadne (parafraseando SOARES, 2015) - que une São Paulo à RMBS considerando-se o turismo em tempos de COVID-19.

Baixada Santista: práticas turísticas como vetor de espalhamento da COVID-19

A relação entre São Paulo e a RMBS, historicamente construída e inerente ao modo de produção capitalista, ganhou novos contornos durante a pandemia e vem sendo remodelada diante das novas condições geradas por ela - particularmente no que se refere ao fenômeno das segundas residências. O binômio motivacional sol e praia, somado a aspectos como a demanda solvável e a pequena distância que separa a capital da Baixada Santista (85 quilômetros, no caso de Santos), levou à maior concentração de segundas residências no país, bem como aos maiores fluxos domésticos de visitação, exceto capitais.

Dados do Instituto Brasileiro de Geografia e Estatística-IBGE, apontam uma concentração de $64,13 \%$ dos domicílios de uso ocasional na porção centro-sul do país (IBGE, 2010). Ainda segundo o Censo Demográfico de 2010, dentre os estados com litoral, São Paulo é disparado aquele que detém a maior concentração de segundas residências, o que corrobora com a somatória de aspectos anteriormente mencionados que caracterizam tal fenômeno e, por conseguinte, caracterizam o uso turístico majoritariamente praticado no território.

Entretanto, identifica-se nuances no tipo de turismo praticado entre os municípios da Baixada, notadamente naqueles da porção central, mais próximos da capital e que sofrem também influência do maior dinamismo econômico da cidade de Santos e de seu complexo portuário. Municípios como Santos, Guarujá, Praia Grande e São Vicente apresentam número significativamente maior de empresas características do turismo em relação aos demais. O turismo de eventos é, por outro lado, um exemplo de uma atividade turística que ocorre de maneira mais acentuada nesses quatro municípios destacados. A título de exemplo, Santos contava com 1.041 empresas do setor de eventos contra apenas 47 desse mesmo segmento no município de Mongaguá11.

Ainda com relação ao fenômeno das segundas residências, tão característico da região, é mister pontuar que muito embora ocorra em números absolutos também elevados para Santos e São Vicente (20.073 e 11.610 respectivamente), a influência que exerce o fenômeno na economia local desses municípios é menor em função da representatividade destes frente aos domicílios particulares permanentes ocupados. Ao

\footnotetext{
${ }^{11}$ Disponível em: https://datasebrae.com.br/total-de-empresas-brasileiras-11-03-2020/. Acesso em 30 agosto de 2020.
} 
contrário, nos municípios de Bertioga e Mongaguá, por exemplo, mais de $60 \%$ dos domicílios são de uso ocasional. ${ }^{12}$

No que se refere ao fluxo rodoviário de veículos de passeio na principal via de interligação entre a capital e os municípios da Baixada Santista, a comparação entre o primeiro semestre de 2019 e o primeiro de 2020 revela um decréscimo de $11 \%$. Percebemos um decréscimo ainda maior (de $45 \%$ ) no comparativo do segundo trimestre (abril a junho), justamente quando se intensificam as medidas restritivas de mobilidade. Já entre os meses de julho a agosto, observa-se uma retomada do fluxo no complexo rodoviário Anchieta-Imigrantes e uma redução de apenas 3\% em relação ao mesmo período do ano anterior. Mesmo com a recuperação no último trimestre - principalmente por conta dos feriados de Natal e Ano Novo - houve uma diminuição anual de 7,6\% no fluxo rodoviário (entre veículos de passeio e comerciais) (ECORODOVIAS, 2021) ${ }^{13}$.

O fato é que o turismo pré-pandemia praticado nos municípios da Baixada Santista, enquanto um reflexo das contradições inerentes ao modo de produção capitalista, forja o uso seletivo de uma determinada porção territorial a fim de atender a determinados interesses e necessidades de uma minoria privilegiada, em detrimento da população local. Esse processo é reforçado no transcurso da pandemia, uma vez que a perspectiva tecnocrata e economicista se perpetua e se intensifica. De um lado, o aumento do fluxo e da permanência dos até então veranistas propicia certo fôlego para a economia das localidades receptoras, movimentando o setor de comércio e serviços. Do outro, traz consigo a sujeição da população local à maior chance de contágio e às consequências da doença. No maior loteamento de segundas residências da América Latina, localizado no município de Bertioga ${ }^{14}$, a Riviera de São Lourenço, um representante dos vendedores ambulantes relata que no mês de junho de 2020, cerca de 25 mil pessoas faziam sua quarentena na localidade ${ }^{15}$. Sem estimativas precisas, as demais secretarias municipais relatam um nítido aumento na movimentação de pessoas e, consequentemente, nos estabelecimentos locais de comércio e serviços ${ }^{16}$. No intervalo de julho de 2019 a junho de 2020 houve um aumento de 64\% na venda de imóveis para quatro municípios da Baixada contemplados no estudo: Santos, Guarujá, São Vicente e Praia Grande (SECOVISP, $2020)^{17}$.

Um olhar sobre como se comportou a arrecadação do Imposto sobre Circulação de Mercadorias e Serviços (ICMS), nos permite aferir a importância que teve a intensificação do fluxo e o aumento da

\footnotetext{
12 Disponível em: https://cidades.ibge.gov.br/. Acesso em 3 de março de 2021.

${ }^{13}$ Disponível em: https://api.mziq.com/mzfilemanager/v2/d/7c109ecb-88c9-441f-91cb-66a8db417120/822e2b0d-97e4-daeb-8a5b9708b4b31c24?origin=1. Acesso em: 20 de fevereiro de 2021

${ }^{14}$ A população estimada municipal para 2020 é de 64 mil pessoas. Disponível em: https://cidades.ibge.gov.br/. Acesso em 3 de março de 2021.

15 Entrevista realizada em junho de 2020 com representante de uma das associações de vendedores ambulantes do município de Bertioga.

16 Informações obtidas a partir de entrevistas realizadas pelos autores com representantes dessas secretarias.

17 Disponível em https://www.secovi.com.br/noticias/vendas-e-lancamentos-de-imoveis-novos-crescem-na-baixada-santista/15080 Acesso em 3 de março de 2021.
} 
permanência nessas localidades. Municípios que, segundo o Instituto de Pesquisas Econômicas Aplicadas $(\text { IPEA, s/d })^{18}$, possuíam, em 2018, alta taxa de dependência econômica do turismo, obtiveram até mesmo um incremento na arrecadação de ICMS durante o período de pandemia. Este é o caso, por exemplo do município de Peruíbe, que teve um incremento de $20 \%$ na arrecadação de ICMS no comparativo entre o ano de 2019 e 2020.

Entretanto, nem todos os municípios da Baixada se comportaram da mesma forma. Guarujá e Bertioga, por exemplo, apresentaram uma maior queda na arrecadação de ICMS em 2020 (10\% e 52\% respectivamente), fato que pode ser o reflexo de uma alta taxa de dependência econômica do turismo, somada a um maior parque hoteleiro e existência de outras empresas características do turismo que tiveram suas atividades suspensas, sobretudo durante os primeiros meses da pandemia.

\section{Análise integrada do turismo no eixo São Paulo-Baixada Santista durante a pandemia}

Entre avanços e retrocessos econômicos, sociais e sanitários, caminhamos para um ano de pandemia com reflexos no setor do turismo que também variaram conforme a fase, contexto e lugar de incidência. No afã de identificar momentos da pandemia vivenciados entre a RMSP e a RMBS, desde o seu início até o momento atual, e aprofundar a análise, propomos, a seguir, algumas fases, assimiladas com base nos dados levantados, além de decretos e notícias veiculadas pela mídia, que ajudam a compor o quadro de um processo em curso, mas que já indica alguns padrões reconhecíveis.

\section{$\underline{1 \text { a fase - os preâmbulos da pandemia entre a RMSP e a RMBS }}$}

Entre as inúmeras incertezas existentes sobre o novo coronavírus desde dezembro de 2019, algo parecia se destacar como verdade: a necessidade de controlar os fluxos e a mobilidade para conter a sua propagação. Com o reconhecimento da transmissão entre humanos, este se torna, em diferentes medidas, o padrão das ações adotadas entre as nações para lidar com o momento (HAESBAERT, 2020). Sendo o turismo definido como um fenômeno social, cultural e econômico que implica no deslocamento de pessoas para locais diferentes daquele em que habitam (UNTWO, s/d) ${ }^{19}$ e uma atividade que consome essencialmente o espaço (CRUZ, 2003), os impactos sobre o setor foram evidentes. O relatório emitido pela Organização Mundial de

\footnotetext{
18 Disponível em: http://extrator.ipea.gov.br/. Acesso em 30 junho de 2020.

19 Disponível em: https://www.unwto.org/glossary-tourism-terms. Acesso em 1 de março de 2021.
} 
Turismo em abril de 2020 ressaltou que se tratava de uma situação histórica sem precedentes, com 100\% dos destinos adotando medidas de restrição a turistas devido à pandemia da COVID-19 (UNTWO, 2020).

Na capital do estado de São Paulo, a quarentena instituída pelo governador João Dória teve início no dia 24 de março por meio do Decreto $\mathrm{n}^{\circ} 64.881$, de 22/03/2020, impondo o fechamento do comércio e de todos os serviços considerados não-essenciais. Por sua vez, o Conselho de Desenvolvimento da Baixada Santista (Condesb), em reunião extraordinária, realizada no dia 16 de março, se antecipou em relação às medidas restritivas, estabelecendo, entre outras, o fechamento de escolas municipais, a suspensão de autorização de entrada para vans e ônibus de turismo e a adoção de medidas de contenção em locais de grande público. ${ }^{20}$ No entanto, as dificuldades se evidenciaram quando, no Guarujá, por exemplo, o final de semana seguinte foi marcado pela ocorrência de aglomerações nas praias. Conforme declaração do expresidente do Condesb e ex-prefeito de Santos, Paulo Alexandre Barbosa: "praia é um espaço de convivência, integração de aproximação. É tudo que nós pretendemos evitar neste momento". Assim, no dia 19 de março, novas ações foram divulgadas, incluindo a proibição total de acesso às praias da Baixada. ${ }^{21}$ Chama particular atenção, portanto, o momento inédito vivido pelos municípios da Baixada que, historicamente relacionados ao turismo de sol e mar e, em diferentes medidas, economicamente dependentes da atividade, foram compelidos durante a pandemia a desestimular a visita de turistas por meio de diferentes estratégias (CARNEIRO, ALLIS, 2021).

Como uma das maneiras de averiguar o seguimento das recomendações impostas, foi instituído o Sistema de Monitoramento Inteligente de São Paulo (SIMI-SP) por meio do decreto $\mathrm{n}^{\circ} 64.963$ de 05 de maio de 2020 - uma parceria com as operadoras de telefonia Vivo, Claro, Oi e Tim e com o Instituto de Pesquisas Tecnológicas (IPT). Através desse sistema de geolocalização foi possível computar as taxas de adesão à quarentena em todo o Estado, bem como possíveis aglomerações. A taxa considerada ideal para o controle da disseminação da COVID-19 e para a eficácia da quarentena foi estabelecida em 70\%, porém, os gráficos de registros do SIMI evidenciam que a capital jamais alcançou essa adesão, com marcas em torno de $59 \%$ entre março e abril. ${ }^{22}$

No que se refere à Baixada Santista, todos os municípios registraram dias de maior adesão à quarentena em abril e, em Mongaguá, Santos e São Vicente, a maior marca de 55\%, 59\% e 68\%, respectivamente, se repetiu em algum momento de maio. Nessa perspectiva, apesar de oscilações conforme o dia da semana com maiores índices predominantemente aos domingos - dias de abril e maio apresentaram a maior taxa de

20 Disponível em: https://www.santos.sp.gov.br/?q=noticia/prefeitos-da-baixada-santista-definem-11-medidas-contra-o-novocoronavirus. Acesso em 2 de março de 2021.

${ }^{21}$ Disponível em: https://www.santos.sp.gov.br/?q=noticia/baixada-santista-impoe-novas-medidas-de-restricao-sobre-o-coronavirus Acesso em 2 de março de 2021.

22 Disponível em: https://www.saopaulo.sp.gov.br/coronavirus/isolamento/. Acesso em 2 de março de 2021. 
adesão à quarentena na capital e na Baixada Santista, coincidindo com os menores fluxos rodoviários de 2020 durante o segundo trimestre ${ }^{23}$.

De maneira geral podemos notar um quadro em que medidas de restrição de circulação foram consideradas, em diversos graus de contundência e com distintos rigores no cumprimento - inclusive com intervenção em instâncias judiciais. No outro sentido, apesar do recrudescimento da pandemia ao longo do primeiro semestre, comportamentos turísticos convencionais - como se não houvesse tamanho impedimento sanitário - pareceram continuar a se manifestar, em alguma medida por conta da natureza das práticas turísticas que se dão na Baixada Santista, com grande participação de turismo de segunda residência. Neste sentido, operam dinâmicas tanto de mobilidade enquanto fluidez (por parte de turistas que não aceitam o impedimento de locomover-se ao litoral, a despeito das restrições legais e mesmo físicas), quanto de mobilidade como friç̧ão, aqui representada por medidas legais, em níveis estadual e municipal, resultando, em vários momentos, em imposição de barreiras físicas para controlar acesso às cidades da Baixada Santista.

Esta, portanto, é uma dinâmica nova, dado o ineditismo de situações que a pandemia impõe, inclusive no campo do turismo. Por isso, seguimos a análise para entender como isso avançou ao longo de 2020, conforme a própria pandemia se desenvolvia com diferentes níveis de gravidade (número de casos e óbitos, limitação de estrutura hospitalar, contestações no plano econômico às restrições de circulação, dentre outros).

\section{$\underline{2 \text { a fase - os realces e os novos contornos entre a RMSP e a RMBS durante a pandemia }}$}

A segunda fase, tida como uma fase de transição, revela a percepção de que a pandemia não acabaria com rapidez e de que a quarentena - com diferentes graus de rigor - se estenderia além das expectativas. Um momento que pode colaborar para identificar o início dessa fase foi o "megaferiado" criado pelo governo do estado de São Paulo como tentativa de melhorar as taxas de isolamento social. Foram antecipados os feriados de Corpus Christi, Consciência Negra e Revolução Constitucionalista, resultando em um longo feriado entre os dias 20 e 25 de maio. Conforme declaração do governador João Dória, a iniciativa baseou-se na percepção de que durante os feriados anteriores os índices de isolamento se elevavam. ${ }^{24}$

\footnotetext{
${ }^{23}$ Disponível em: https://ri.ecorodovias.com.br/informacoes-aos-investidores/fundamentos-e-planilhas/. Acesso em 2 de março de 2021.

24 Disponível em: https://g1.globo.com/sp/sao-paulo/noticia/2020/05/18/para-aumentar-isolamento-social-governo-de-sp-queradiantar-feriado-de-9-de-julho-para-proxima-segunda-feira.ghtml. Acesso em 1 de março de 2021. Para mais detalhes e uma análise sobre este momento, consultar Carneiro, Allis (2021).
} 
No entanto, a ação não surtiu os efeitos desejados. Apesar das restrições e dos apelos para que a população permanecesse em suas residências, as taxas não atingiram os níveis considerados ideais para a capital. O Condesb, por sua vez, deliberou a não-adesão ao feriado prolongado e demandou apoio do Governo Estadual e também iniciativas em nível local (municipalidades do litoral paulista) para a instalação de bloqueios com o intuito de atuar na restrição de entrada de veículos nos municípios da Baixada. De fato, algumas barreiras foram implantadas e atuaram com critérios variados, seja restringindo o acesso a veículos com placas de fora dos municípios e orientando o retorno à cidade de origem, seja por meio de bloqueios sanitários com informações educativas. ${ }^{25}$

O feriado da Independência (7 de setembro) foi um outro exemplo claro desse movimento do planalto em direção à Baixada e dos conflitos de interesses envolvendo turistas, comerciantes, população local e governantes, entre outros sujeitos sociais que compõem esse cenário. Conforme amplamente noticiado pela imprensa, praias da Baixada Santista ficaram lotadas de turistas durante o feriado e, segundo a concessionária Ecovias, foi registrado um fluxo de mais de 187 mil veículos no Sistema Anchieta-Imigrantes em direção à Baixada no feriado da Independência, na principal rota de chegada às praias dessa região, partindo de São Paulo $^{26}$. Na ocasião, a Operação Independência, criada pelo Governo Estadual, teve o intuito de fiscalizar os municípios para garantir o cumprimento das medidas sanitárias, patrulhar as rodovias, entre outras ações, tais como conscientizar a população por meio do uso de megafones. ${ }^{27}$

Apesar dos esforços, os resultados se revelaram em seguida: no período de 13 a 19 de setembro, um aumento de $41,8 \%$ nos casos e $82,5 \%$ nas mortes em relação à semana anterior na Baixada Santista. ${ }^{28}$

Vale destacar que, em meados de 2020, apesar da seriedade da pandemia no Brasil, havia uma sensação de estabilização do quadro, ainda que o Brasil tivesse atingido um platô em número de casos e mortes portanto, não se tratava de melhoria do quadro, que voltaria a se agravar até setembro de $2020^{29}$. Assistiu-se, contudo, a crescente demanda de setores econômicos pela flexibilização da quarentena, afora a minimização da gravidade no nível político, especialmente emanadas do plano federal.

Enquanto isso, governantes locais buscavam formas e estratégias legais para refrear esses fluxos e evitar a circulação do vírus pelos territórios de seus municípios, algo que ficou evidente nas entrevistas realizadas

25 Disponível: https://g1.globo.com/sp/santos-regiao/noticia/2020/05/21/litoral-de-sp-reforca-os-bloqueios-durante-megaferiadoem-sp.ghtml. Acesso em 1 de março de 2021.

${ }_{26}$ Disponível em https://www.ecovias.com.br/noticias/feriados/ecovias-registra-passagem-de-mais-de-187-mil-veiculos-no-sistemaanchieta-imigrantes-durante-feriado-da-independencia-197888. Acesso em Acesso em 2 de março 2021

27 Disponível em: https://www.saopaulo.sp.gov.br/ultimas-noticias/governo-do-estado-atualiza-informacoes-sobre-o-combate-aocoronavirus-2/. Acesso em 1 de março de 2021.

28 Disponível em: https://saude.estadao.com.br/noticias/geral,estudo-aponta-aumento-de-casos-de-covid-19-na-regiao-decampinas-e-na-baixada-santista,70003450323 Acesso em 10 de março de 2021.

${ }^{29}$ Os dados e estatísticas sobre COVID diferem em função das fontes. Para mais detalhes, consultar o dashboard da Fundação Oswaldo Cruz (https://bigdata-covid19.icict.fiocruz.br) ou a portal Worldmeter (https://www.worldometers.info/coronavirus/country/brazil/) . 
até o momento com representantes do poder público do setor turístico de alguns municípios. Não obstante, esta se conformou como uma tarefa inglória diante do clamor de comerciantes locais e das pressões emanadas de uma massa de turistas ávidos por vivenciar, ainda que por alguns momentos, uma aparente e pretensa suspensão da crise. Esses conflitos se repetiram em feriados seguintes como 12 de Outubro, Finados, Natal, Ano Novo e, mais recentemente, no Carnaval 2021, mesmo diante da suspensão do feriado desse período pelo governo do estado.

Nesse período se acentuaram os diálogos e mensagens sobre retomada da economia e, no dia 4 de junho de 2020, foi lançado pelo Ministério do Turismo o selo "Turismo Responsável - limpo e seguro", compreendido como um incentivo para que as pessoas sintam mais segurança ao viajar, uma vez que a adesão ao selo pressupõe o seguimento de protocolos para a prevenção da COVID-1930. Conforme declaração do Ministro do Turismo na ocasião, Marcelo Álvaro Antônio, os próprios turistas seriam os responsáveis por fiscalizar a implementação das medidas e protocolos, ${ }^{31}$ evidenciando parte do descaso e negligência do governo federal com a sua responsabilidade no que se refere ao controle da pandemia.

Sendo assim, essa tendência à normalização de um "turismo de pandemia" se manifesta ainda durante o ano de 2020, quando o setor sofria seus reveses e a pandemia ainda inspirava preocupações sanitárias. Um fato que contribui para esse entendimento é o exemplo das plataformas de venda de hospedagem - como AirBnB e Booking.com -, que começaram a construir e a circular uma narrativa alternativa aos longos deslocamentos turísticos, focando em viagens de proximidade ou mesmo experiências locais, com o argumento da pretensa segurança.

Também nesse período foi se revelando uma tendência: o aumento de indivíduos que passaram a residir de maneira permanente em suas segundas residências no litoral. As restrições e o medo de frequentar locais da Capital, aliado às facilidades do home-office para certos grupos de profissionais, propiciaram esse tipo de mudança e podem, em certa medida, contribuir para explicar o aumento do ICMS em alguns municípios, conforme visto em tópico anterior. Ou seja, parecia haver algumas condicionantes para normalizar ou mesmo incentivar alguma forma de turismo, mesmo quando não havia perspectiva clara de vacinação (especialmente no Brasil) e a situação epidemiológica não era propriamente tranquila.

\section{$\underline{\text { 3a fase - a consolidação do "turismo da pandemia" entre a RMSP e a RMBS }}$}

\footnotetext{
${ }^{30}$ Disponível em: http://antigo.turismo.gov.br/seloresponsavel/ Acesso em 3 de março de 2021.

31 Disponivel em: https://www.mercadoeeventos.com.br/_destaque_/slideshow/ministerio-do-turismo-lanca-selo-turismoresponsavel/ Acesso em 3 de março de 2021.
} 
A terceira fase identificada - em um esforço de delimitação, com início por volta de dezembro - revela que, se a RMSP e a RMBS são histórica e profundamente interligadas, o contexto pandêmico reforça essa relação e adiciona novos elementos a ela. Diante das restrições e do medo das viagens mais longas e que tornariam necessário o uso de transportes coletivos - tais como ônibus ou aviões - a Baixada Santista parece se consolidar como a válvula de escape para turistas residentes na capital e em seu entorno metropolitano, aliviando as pressões de milhares de turistas que se direcionaram a um tempo de lazer na praia com vistas a momentos de abstração do stress da vida cotidiana e de tragédias que a pandemia trouxe consigo. Abstração que se revela contraditória, uma vez que tanto a RMSP quanto a RMBS enfrentam os mesmos conflitos e tragédias, cada uma com as suas especificidades. Sendo assim, se o fluxo de visitação doméstica entre as duas regiões já era muito expressivo em período anterior, as condições propiciadas pela pandemia da COVID-19 parecem, em grande medida, potencializar essa dimensão.

Conforme comentado anteriormente, a presença marcante de segundas residências nos municípios da Baixada Santista, utilizadas para uso próprio das famílias ou para locação explica, em parte, este fenômeno de fuga da metrópole - mas não da pandemia, ressalte-se - em direção ao litoral. As pressões psicológicas e emocionais geradas pelo confinamento, ainda que de maneira parcial, podem ser compreendidas como fatores propulsores desses fluxos.

Com base nos dados e informações expostos anteriormente, podemos dizer que o fenômeno das segundas residências possui um papel central na análise sobre esse momento: por um lado contribuiu para atenuar as agruras econômicas, sobretudo para aqueles municípios mais dependentes economicamente desta população flutuante. Por outro, é bastante provável que tenha sido um coadjuvante no espalhamento do vírus, além de reforçar a subsunção da humanidade à uma perspectiva econômica segregadora.

Aqui, a ideia de "mobilidades (in)justas" (SHELLER, 2018) faz mais sentido do que nunca: esses viajantes transitam por diferentes identidades (morador local, por ter residência em um destino litorâneo, e também turista ou veranista, uma vez que a casa principal fica em outra localidade), e com isso garantem uma fluidez pelo território, no momento em que justamente a circulação é motivo de preocupação. Assim, ao mesmo tempo que buscam uma justa segurança, ao deixaram suas residências de origem (em grande medida, na Capital), produzem outros riscos para aquelas porções de moradores que, sem opção, estão atados ao território que serve de refúgio e fuga para outros.

\section{CONSIDERAÇÕES FINAIS}

Como se pretendeu mostrar neste artigo, a compreensão dos efeitos da pandemia da COVID-19 sobre o turismo nas localidades estudadas passa pelo reconhecimento das imbricadas e complexas relações que 
envolvem duas regiões metropolitanas territorialmente distintas, mas histórica, social e economicamente unidas por mobilidades de diferentes naturezas.

Considerando os processos ainda em curso, reconhecemos, por outro lado, a necessidade de continuidade das análises e o aprofundamento das pesquisas na busca pelo desvendamento de suas particularidades em se tratando dos casos estudados.

Como expressão do dinamismo dos acontecimentos, podemos citar, a título de exemplo que, no mais recente e atual momento da pandemia (março de 2021), quando os números de contágios e óbitos batem recordes diários, o governo de São Paulo anunciou o recrudescimento de todo o estado para a fase vermelha e, na sequência, para a fase emergencial, a mais restritiva do Plano São Paulo de combate à COVID-19. Além disso, o prefeito da cidade de São Paulo decretou um megaferiado de 10 dias, ao adiantar feriados deste e do próximo ano e emendá-los com o feriado da Páscoa. Antes mesmo desta medida tomada pela prefeitura de São Paulo, o atual prefeito da cidade de Santos e presidente do Condesb já apontava para a necessidade de novas medidas restritivas com vistas justamente a conter a intensificação e um novo afluxo dos moradores da capital proprietários de segunda residência na região. Rogério Santos demonstra preocupação, pois “[a] característica da Baixada Santista, além de turística, é a segunda residência para muitas pessoas e tem a peculiaridade de, neste momento, estar na fase amarela, o que traz certa segurança para as pessoas, por causa dos números [mais baixos] ${ }^{32}$.

Ademais, cabe destacar, mais uma vez, a importante articulação entre os municípios da Baixada Santista e outras localidades do estado no período de pandemia o que, quase um ano depois, ainda se revela complexo. A própria ideia de "turismo de pandemia" - que emerge e segue um curso de normalização representa uma violência e uma ameaça à coletividade, por mais que, na vertente econômica, seja apontado como uma resposta imediata. Neste sentido, observar a dinâmica de mobilidades turísticas no contexto metropolitano indica um profícuo exercício para entender possíveis desdobramentos ao próprio formato, às narrativas e às forças econômicas que contribuem para a estruturação do turismo contemporâneo.

Alinhados com a pesquisadora Zeynep Tufekci (2020), podemos dizer que as práticas turísticas observadas se conjugam para formar um "teatro da pandemia". ${ }^{33}$ A expressão remete a medidas essencialmente ineficazes, mas que, teatralmente efetuadas, transmitem uma falsa sensação de segurança aos indivíduos. Trata-se, por exemplo, do adquirido hábito de alguns comércios e restaurantes de permitirem

32 Disponível em https://noticias.uol.com.br/saude/ultimas-noticias/redacao/2021/03/04/litoral-paulista-baixada-santista-fasevermelha-invasao.htm. Acesso em 4 de março de 2021.

33 Disponível em: https://www.theatlantic.com/health/archive/2020/04/closing-parks-ineffective-pandemic-theater/609580/. Acesso em 2 de março de 2021. 
a entrada ilimitada de pessoas, justificando esse fato com a ação de checar a temperatura corporal de cada uma.

Em um contexto em que pesquisadores do mundo inteiro atestam a transmissão assintomática da COVID-19, essa atitude diz muito mais sobre a mensagem simbólica que se deseja passar - a retomada da economia e uma pretensa "normalidade" - do que à efetividade do controle da pandemia. São mensagens contraditórias que se imbricam ao turismo e, se inserem, consequentemente, no bojo das contradições próprias do modo de produção capitalista.

\section{REFERÊNCIAS}

ALLIS, Thiago. Viajantes, visitantes, turistas... Em busca de conceitos em um mundo urbano. Caderno Virtual de Turismo. Edição especial: Hospitalidade e políticas públicas em turismo. Rio de Janeiro, v. 14, supl.1, s.23-s.38, nov. 2014.

AMENDOLA, Gilberto. Roteiro pela Serra da Cantareira: opções para comer bem e curtir a natureza. O Estado de São Paulo, São Paulo, 11 dez. 2020. Disponível em: https://viagem.estadao.com.br/noticias/geral,roteiro-pela-serra-da-cantareira-opcoes-paracomer-bem-e-curtir-a-natureza,70003547103. Acesso em 2 de março de 2021.

ARROYO, Mónica. São Paulo e os fluxos internacionais de mercadorias: a espessura de uma região metropolitana. In: Carlos, Alessandra Fani; Oliveira, Ariovaldo Umbelino (orgs.). Geografias de São Paulo: a metrópole do século XX. São Paulo: Contexto, 2004, p. 85-104.

AUGÉ, Marc. Por uma antropologia da mobilidade. Maceió: EDUFAL, 2010.

BRENNER, Neil. Thesis on urbanization. Public Culture, n. 25, v. 1, 2013, p. 85-114,

CARNEIRO, Juliana; ALLIS. Thiago. Como se move o turismo durante a pandemia da COVID-19? Revista Brasileira de Pesquisa em Turismo, vol. 15, n. 1, 2021 2212. Disponível em http://dx.doi.org/10.7784/rbtur.v15i1.2212. Acesso em 3 de março de 2021.

CASTRO, Iná Elias de. O problema da escala. In: Castro, Iná Elias de, Gomes, Paulo Cesar da Costa, Corrêa, Roberto Lobato. Geografia: conceitos e temas. Rio de Janeiro: Bertrand Brasil, 2002, p. 117-140.

CORBIN, Alain. Território do vazio: A praia e o imaginário ocidental. São Paulo: Companhia das Letras, 2008.

CRESSWELL, Tim. On the Move. Londres: Routledge, 2006.

CRUZ, Rita. Introdução à Geografia do Turismo. 2. ed. São Paulo: Roca, 2003.

ECORODOVIAS. Boletim $4^{\circ}$ Trimestre de 2020. Disponível em: https://api.mziq.com/mzfilemanager/v2/d/7c109ecb-88c9-441f-91cb66a8db417120/822e2b0d-97e4-daeb-8a5b-9708b4b31c24?origin=1. Acesso em 20 de fevereiro de 2021.

HAESBAERT, Rogério. Reflexões geográficas em tempos de pandemia. Espaço e Economia [Online], 18 | 2020, post online no dia 17 abril 2020. Disponível em: URL:http://journals.openedition.org/espacoeconomia/11826; DOI:

https://doi.org/10.4000/espacoeconomia.11826. Acesso em 6 de março de 2021.

IBGE - INSTITUTO BRASILEIRO DE GEOGRAFIA E ESTATÍSTICA, 2000. Resultado dos Dados Preliminares do Censo - 2010. Disponível em: https://cidades.ibge.gov.br/\#/. Acesso em: 08 de março de 2021.

KAUFMANN, Vincent; RAVALET, Emmanuel; DUPUIT, Élodie (orgs.), Motilité et mobilité: mode d'emploi, Neuchâtel: Alphil, 2015.

LENCIONI, Sandra. Urbanização difusa e a constituição de megarregiões - o caso de São Paulo-Rio de Janeiro. Revista e-Metropolis, n. 22, Ano 6, p. 6-15, 2015.

Da cidade e sua região à cidade-região. In: Silva, José Borzachiello da; Lima, Luiz Cruz; Elias, Denise (orgs.) Panorama da geografia brasileira, vol. 1. São Paulo: Annablume, 2006, p. 65-75.

MOLINA, Natalia. Staycation: a experiência de ser turista na própria cidade. O Estado de São Paulo, São Paulo, 14 set. 2020. Disponível em: https://viagem.estadao.com.br/noticias/geral,staycation-a-experiencia-de-ser-turista-na-propriacidade,70003434441. Acesso em 2 de março de 2021. 
MORAES, Antonio Carlos Robert. Notas metodológicas sobre metropolização e a metrópole paulistana. In: Carlos, Alessandra Fani; Oliveira, Ariovaldo Umbelino (orgs.). Geografia das metrópoles. São Paulo: Contexto, 2006, p. 23-29.

REIS, Nestor Goulart. Dispersão urbana e modernização capitalista. Revista Cidades, v. 15, n. 21, 2015, p. 91-107.

OBSERVATÓRIO DO TURISMO DA CIDADE DE SÃO PAULO. Impactos da pandemia de Covid-19 no turismo de São Paulo. Disponível em http://www.observatoriodoturismo.com.br/pdf/01BoletimSPCovid 05mai.pdf. Maio/2020. Acesso em 1 de março de 2021.

OBSERVATÓRIO DO TURISMO DA CIDADE DE SÃO PAULO. Impactos da pandemia de Covid-19 no turismo de São Paulo. Disponível em http://www.observatoriodoturismo.com.br/pdf/BOLETIM SP COVID 19 Edição 2.pdf. 2o Semestre/2020. Acesso em 2 de março de 2021.

SABINO, André L. Bertioga e a hegemonia do capital imobiliário - um foco sobre a Praia de Indaiá. In: Cruz, Rita de Cássia Ariza da. Geografias do turismo: de lugares a pseudo-lugares. São Paulo: Roca, 2007, p. 66-84.

SÃO PAULO. FUNDAÇÃO SEADE. Portal de Estatísticas do Estado de São Paulo. Disponível em https://produtos.seade.gov.br/produtos/projpop/index.php. Acesso em 23 de fevereiro de 2021.

SEABRA, Odette. A muralha que cerca o mar. 1979. 122f. Dissertação (Mestrado em Geografia), Faculdade de Filosofia, Letras e Ciências Humanas, Universidade de São Paulo, 1979.

SHELLER, Mimi. Mobility justice: the politics of movement in an age of extremes. New York: Verso, 2018.

From spatial turn to mobilities turn. Current Sociology, 2017, 1-17.

SHELLER, Mimi; URRY, John. The new mobilities paradigm. Environment and Planning A: Economy and Space, vol. 38, n. 2, 2006, p. 207-226.

SOUZA, Marcelo Lopes de. Alguns aspectos da dinâmica recente da urbanização brasileira. In: FERNANDES, E.; VALENÇA, M. Brasil urbano. Rio de Janeiro: Mauad, 2004, p. 57-74.

UNWTO. Glossary of Tourism Terms. Disponível em https://www.unwto.org/glossary-tourism-terms. Acesso em 01 de março de 2021.

URRY, John. Sociology Beyond Societies: mobilities for the twenty-first century. London: Routledge, 2000.

TUFEKCI, Z. Coronavírus: COVID-9. Keep the parks open. The Atlantic. 7/04/2020. Disponível em: https://www.theatlantic.com/health/archive/2020/04/closing-parks-ineffective-pandemic-theater/609580/. Acesso em 02 de março de 2021. 